\section{Interstitial deletion of the long arm of chromosome 4 in a patient with mental retardation and abnormal phenotype}

The patient (fig 1) was an 11-year-old Caucasian boy, the second child of non-consanguineous parents aged 21 and 27 at the time of his conception. His elder sister was normal and died accidentally at the age of 7 years. The outcome of the third pregnancy of the couple was an anencephalic male.

The proband was born after an uneventful term pregnancy and was delivered with the aid of forceps. His birth weight was $3100 \mathrm{~g}$ and the neonatal period was normal. During the first year of life, retardation of developmental milestones and craniosynostosis were detected and craniostomies were performed at 13 and 24 months of age.

Now, at the age of 11 , his IQ is 60 . Physical examination revealed short stature $(112 \mathrm{~cm},-3.8 \mathrm{SD})$, small head circumference $(49.5 \mathrm{~cm},-2.5 \mathrm{SD})$ and the following minor anomalies of skull and face: brachicephaly, low posterior hair line, facial asymmetry, prominent glabella, shallow orbital ridges, deviated nose, long philtrum, small mouth, irregular placement of the teeth, high arched palate, and micrognathia. The ears were small, low set, and posteriorly rotated. Small testes, widely spaced nipples, and short nails were also noted. Neurological examination showed bilateral Babinski signs.

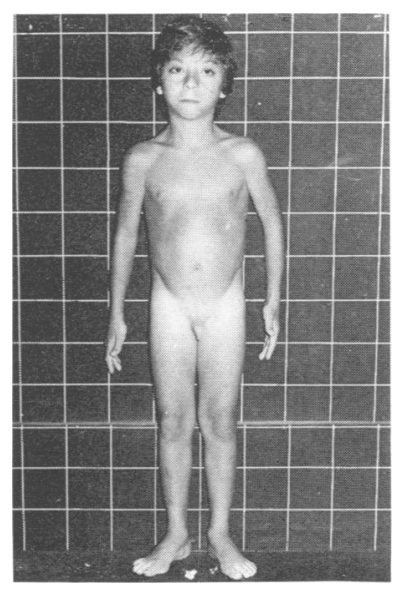

FIG 1 The proband, aged 11 years.

Received for publication 8 April 1982.

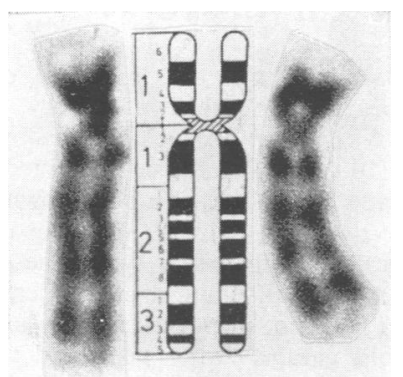

FIG 2 Normal chromosome 4 (left), diagrammatic representation of chromosome 4 according to Paris Conference (middle), and del(4) (q27q31) (right).

Cardiological, ophthalmological, and audiometric examinations were normal. $X$-rays of the skull showed ostiotomy sequelae.

Dermatoglyphic examination showed distal and ulnar displacement of the axial triradii. There were eight whorls and two ulnar loops on the fingertips and a simian crease on the right hand. The remaining flexion creases were normal.

Peripheral blood lymphocytes were cultured according to the method of Moorhead et al. ${ }^{1} \mathrm{G}$ banding ${ }^{2}$ was applied to identify a chromsome $B$ with a shorter than normal long arm detected through conventional staining. The banding pattern obtained showed an interstitial deletion of the long arm of a chromosome 4 with breakpoints at q27 and q31. The remaining chromosomes were normal. The karyotype, according to the 1972 Paris Conference, $^{3}$ was: $46, X Y, \operatorname{del}(4)(4 p t e r \rightarrow 4 q 27:: 4 q 31 \rightarrow$ 4qter) (fig 2). The parents' chromosomes were normal.

\section{María del Valle Torrado, JosÉ DANIEJ. LABARTA, AND ANA María Migliorini Fundación de Genética Humana, Salta 661, 1074 Buenos Aires, Argentina.}

\section{References}

1 Moorhead PS, Nowell PC, Mellman WJ, Battips DM, Hungerford DA. Chromosome preparations of leucocytes cultured from human peripheral blood. Exp Cell Res 1960;20:613-6.

2 Seabright M. A rapid banding technique for human chromosomes. Lancet 1971 ;ii:971-2.

3 Paris Conference. Standardization in human cytogenetics. Birth Defects 1972;8: No 7.

Requests for reprints to $\mathrm{Dr} \mathbf{M}$ del Valle Torrado, Fundación de Genética Humana, Salta 661, 1074 Buenos Aires, Argentina. 